\title{
A construção de um modelo de saúde complexo e transdisciplinar
}

\author{
The construction of a complex and transdisciplinary health model
}

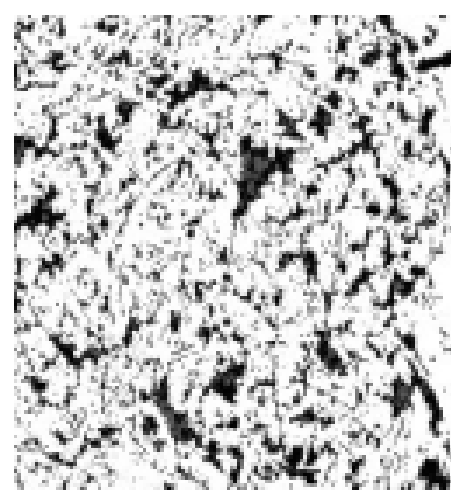

Regina Stella Spagnuolo ${ }^{1}$ Ivan Amaral Guerrini ${ }^{2}$

Ao longo de sua experiência profissional, os educadores em saúde e das áreas assistenciais têm verificado e vivenciado o desenvolvimento da saúde enquanto um bem universal. Tanta luta por mudanças, por quebra de paradigmas, luta por um ideal integrador e não excludente como se tem vivido nestas últimas décadas, e a saúde continua doente... Ora em estado grave, ora em convalescença! Mas os profissionais de saúde sempre estiveram a postos, perseverantes no juramento pretérito, porém vivo em arquétipos individuais e coletivos. Nessa caminhada, percebeu-se aos poucos que o saber começou a pular os muros das academias, na tentativa ainda incipiente, porém determinada, de aproximar a teoria da práxis, levando até o usuário do sistema de saúde uma proposta mais inclusiva e de acesso universalista, que pudesse, enfim, sair do discurso politicamente correto e ser contextualizado em ações que realmente mudassem os indicadores de saúde (Lobo Neto et al., 2000). Sabia-se que seria um processo longo, que ansiedades e desânimos estariam pululando a cada tempo, mas a reconstrução do Sistema Único de Saúde (SUS) sob um novo olhar, finalmente, estava por vir. O cuidar, na visão complexa, mudando a ótica com que se está acostumado a conceituar a saúde, emerge da concepção do ser humano visto como um sistema aberto e envolvido numa rede (Boff, 1997; 2000). Mas, na prática, o que seria o "cuidar" sob este novo olhar? O que seria a promoção da saúde numa visão transdisciplinar, conforme salientado por Nicolescu (2000), Morin \& Le Moigne (2000) e Morin (2001)? Após o advento dessa nova visão, não se pode mais ver o Homem de forma fracionada, em partes estudadas por disciplinas pontuais ou simplesmente justapostas, o que denotaria a inter e a multidisciplinaridade (Nicolescu, 2000). Percebe-se agora

${ }^{1}$ Enfermeira responsável pela Unidade de Saúde da Família no Jardim Iolanda, Secretaria Municipal de Saúde de Botucatu; mestranda do curso de Pós-Graduação em Saúde Coletiva, Faculdade de Medicina de Botucatu, Unesp. <rstella10@yahoo.com.br>

${ }_{2}^{2}$ Professor, Departamento de Física e Biofísica, Instituto de Biociências de Botucatu, Universidade Estadual Paulista - Unesp. <guerrini@ibb.unesp.br>

${ }^{1}$ Rua Heitor Quintino de Carvalho, 414

Altos do Paraíso - Botucatu, SP

18.610-037 
no arcabouço científico deste novo milênio que, ainda que esta afirmação soe como óbvia, só existe um mundo em que todos estão inseridos, e este mundo é um todo maior que a soma de todas as suas partes. Entender a saúde neste novo olhar requer enfrentar desafios para a academia, para o serviço, para os usuários e para os gestores. Principalmente porque os profissionais que hoje atuam foram formados, em sua grande maioria, num contexto de ciência reducionista e de especialização, tendo por base os fundamentos da ciência clássica (Huertas, 1996). Eis, portanto, por caminhos não esperados, a oportunidade de integração que tanto se sonhou! Esse olhar complexo e dinâmico oferece a oportunidade de uma ação integrada que inclui as diferentes dimensões da experiência humana: a subjetiva, a social, a política, a econômica e a cultural, colocando, portanto, a serviço da saúde, os saberes produzidos nos mais diferentes campos do conhecimento. Assim, entende-se que promover a saúde é saber lidar com as diversas condições sócio-econômicas dos segmentos populacionais da sociedade. É enfrentar a pobreza e toda a desestruturação em seu entorno que são marcadas, simultaneamente, pela falta de emprego, de infra-estrutura adequada às necessidades humanas (água potável, destino adequado do lixo e esgoto), pela poluição dos ambientes, pelas carências alimentares e educacionais (Matus, 1997). É, portanto, lidar com diferentes, e até mesmo opostos estilos de vida, buscando transcendê-los (Nicolescu, 2000). É saber lidar com as formas de viver emergentes e constituídas nas sociedades modernas e agora, em especial, num novo momento quando emerge a "Estratégia de Saúde da Família", que coloca o cuidar do ser humano no coração das famílias.

Estariam os profissionais de saúde preparados para entender e para se tornar empáticos a essas mais diversas micro-culturas se não se inverter a lógica de como ainda se vê o ser humano e suas famílias? Nota-se que até mesmo os segmentos mais favorecidos da população perdem de vista o que é uma vida saudável, integrativa, adaptando-se a uma forma de vida sedentária e estressante, geradora de angústias, ansiedades e depressão. Esses sentimentos são expressões legítimas de insatisfações e têm como conseqüência, muitas vezes, comportamentos não compreendidos pelos próprios profissionais de saúde. Esses comportamentos, ao mesmo tempo que têm origem em padrões passados, principalmente da família de origem, se retro-alimentam com as condutas repetitivas, necessitando serem reconhecidos para, em seguida, serem alterados de forma consciente (Nicolescu, 2000; Briggs \& Peat, 2000). Não se pode, por outro lado, se esquecer do trabalho coletivo, já que a sociedade é também complexa, lida com incertezas e é capaz de se auto-organizar (Boff, 2000). Pergunta-se, então: até onde se pode intervir no processo saúde-doença? E, neste momento histórico, de que forma? O hedonismo, que se tornou uma das principais características das sociedades modernas industrializadas, acaba muitas vezes desmobilizando pessoas e grupos sociais para uma luta coletiva por melhores condições de vida, descaracterizando a necessidade de resgate e de revaloração de sentimentos como a solidariedade e a ética. Nesse campo, entretanto, a promoção de uma saúde mais integrativa por meio de esforços emergentes e localizados, já começa a contribuir, capacitando as comunidades, compartilhando o saber técnico que, confrontado com o saber popular, pode criar condições para a tomada de consciência das situações de saúde das comunidades envolvidas.

Está no cerne do caos criativo que essas variáveis, atuando em conjunto, possibilitem a construção de estratégias de enfrentamento dos problemas, passando também a ver a sociedade sob um olhar integrativo e interativo, numa dimensão muito mais que inter ou multidisciplinar, ou seja, a vivência transdisciplinar (Briggs \& Peat, 2000). Esses novos termos, principalmente em áreas de educação e saúde, têm sido usados com freqüência cada vez maior na literatura atual (Guerrini, 2003; Watanabe, 2003). Colocam-se, assim, essas relações em um sistema total, sem quaisquer limites rígidos entre os saberes para compreensão do mundo atual que é a unidade do conhecimento. Nessa nova ótica, aprende-se também a lidar com a política e a administração pública, cuja gestão estatal é geralmente fragmentada, reducionista, elaborando programas de saúde que muitas vezes não contemplam a realidade e a cultura local (Matus, 1997). O que se vivencia hoje é um imenso, incomensurável desafio de desencadear um processo amplo e complexo de parcerias, atuações intersetoriais e participações populares, que otimizem os recursos disponíveis e garantam sua aplicação em políticas que respondam mais efetiva e integradamente às necessidades das comunidades. Contextualizada na prática, essa nova visão pressupõe uma sociedade civil mais organizada, as instituições públicas e privadas 
somando esforços no sentido de uma atuação conjunta que possibilite ir além das barreiras e antagonismos e alcançar resultados que se traduzam em mais e melhores condições de vida para a população. A integração ensino-serviço-comunidade está, pois, inserida no contexto em que se escreve este artigo. A saúde complexa e transdisciplinar aqui proposta, como o próprio nome diz, deverá sempre estar interagindo e trocando saberes, numa dinâmica construtiva e criativa, de forma essencialmente transdisciplinar, sem mais as rígidas disputas do passado, sem decisões estanques que favoreçam apenas este ou aquele segmento. É isso que os profissionais de saúde conscientes da nova visão da ciência e da vida tanto esperam! A troca dos saberes, o aprendizado constante, a construção contínua de um novo olhar, desta vez dinâmico, complexo e transdisciplinar para permitir que esta se recupere do estado convalescente. Busca-se, com isso, um amadurecimento de todos os segmentos, fazendo cada um o seu papel e conjuntamente construindo e consolidando experiências que requerem um conjunto de estratégias de apoio, transcendendo os antagonismos. Só assim será possível promover a expansão das ações, implementando cada vez mais um modelo de atenção integral às famílias por meio de um legítimo "promover" de ações saudáveis, gerando novas práticas profissionais sustentadas por esse modelo tão sonhado.

Este artigo se resume, portanto, num grito de profissionais que, ao mesmo tempo que têm se envolvido nas teias da nova ciência sistêmica aplicada a organismos vivos (Kitano, 2002), vêem nessa nova face da ciência do século XXI, a chance concreta de unir os saberes na busca de soluções mais adequadas às questões atuais de saúde. Nessa rede, não há lugar para conhecimentos preferenciais e nem mesmo para posições grupais predominantes, mas para a cooperação em busca do desenvolvimento sustentável que é tão dinâmico quanto complexo.

\section{Referências}

BOFF, L. A águia e a galinha: uma metáfora da condição humana. Rio de Janeiro: Vozes, 1997.

BOFF, L. A voz do arco-íris. Brasília: Letraviva, 2000.

BRIGGS, J.; PEAT, F. D. A sabedoria do caos. Rio de Janeiro: Editora Campus, 2000.

GUERRINI, I. A. Sobre o complexo e o transdisciplinar. Sci. Am. Br., v. 2, n.19, p.11, 2003.

HUERTAS, F. Entrevista com Carlos Matus: o método PES. São Paulo: FUNDAP, 1996.

KITANO, H. Systems biology: a brief overview. Nature, v. 295, p.1662-4, 2002.

MATUS, C. Adeus, senhor presidente: governantes e governados. São Paulo: FUNDAP, 1997.

MORIN, E.; LE MOIGNE, J-L. A inteligência da complexidade. São Paulo: Fundação Peirópolis, 2000.

MORIN, E. A religação dos saberes. Rio de Janeiro: Bertrand Brasil, 2001.

NICOLESCU, B. Manifesto da transdisciplinaridade. Brasília: UNESCO, 2000.

LOBO NETO, F. J. S.; PRADO, A. A.; FONTANIVE, D. A.; SILVA, P. T.; PROVENZANO, M. E.; MOULIN, M. N.; LOPES, A.; R. C.; COELHO, C. A. G.; BOMFIM, M. I. R. M.; TORREZ, M. N. F. B.; ROMANO, R. A. T.; PIMENTEL, M. R. A. R.; GOULART, V. M. P. Formação pedagógica em educação profissional na área de saúde: Enfermagem. Brasília: Ministério da Saúde; Rio de Janeiro: Fundação Oswaldo Cruz, Escola Nacional de Saúde Pública, 2000.

(Educação, Conhecimento, Ação, 3).

WATANABE, M. Going multidisciplinary. Nature, v. 425, p.542-3, 2003. 


\section{ESPAÇO ABERTO}

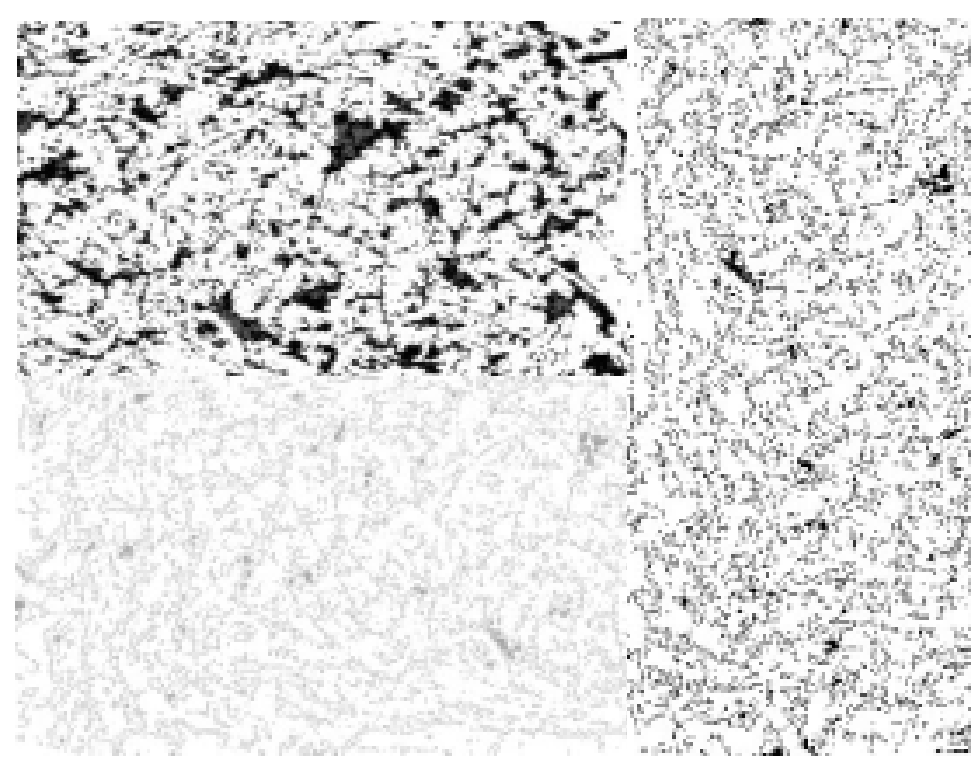

Health as a dynamic, coherent and constructive state of the living being is the basis of the proposal put forth in this essay. From this standpoint, a systemic and integrative view of the human being that is cared for through daily healthcare practices is proposed, based on the concepts of researchers and educators of the last few decades. The concepts of chaos, complexity, transdisciplinarity and auto-organization are introduced and found to make more sense as themes that provide guidance for the suggested procedures. Ways of promoting health, thus defined, are discussed in connection with practical circumstances, including the current official Family Healthcare Strategy program.

KEY WORDS: Chaos; health; complexity; transdisciplinarity; helath promotion.

A saúde como um estado dinâmico coerente e construtivo do ser vivo é o fundamento da proposta deste texto. Nessa ótica, uma visão sistêmica e integrativa do ser humano a ser cuidado na prática diária da saúde está sendo proposta com base nos conceitos de pesquisadores e educadores das últimas décadas. Conceitos de caos, complexidade, transdisciplinaridade e autoorganização são introduzidos e fazem mais sentido como temas orientadores dos procedimentos sugeridos. Maneiras de promover a saúde assim compreendida são discutidas em algumas situações práticas, incluindo o atual programa oficial da Estratégia da Saúde da Família.

PALAVRAS-CHAVE: Caos; saúde; complexidade; transdisciplinaridade; promoção da saúde.

La salud como un estado dinámico coherente y constructivo del ser vivo es el fundamento de la propuesta de este texto. Desde esa óptica, está siendo propuesta, con base en los conceptos de investigadores y educadores de las últimas décadas, una visión sistémica e integrativa del ser humano a ser cuidado en la práctica diaria de la salud. Los conceptos de caos, complejidad, transdisciplinariedad y autoorganización son introducidos y adquieren más sentido como temas orientadores de los procedimientos sugeridos. Las maneras de promover la salud así comprendida son discutidas en algunas situaciones prácticas, incluyendo el actual programa oficial de la estrategia de la salud familiar.

PALABRAS CLAVE: Caos; salud; sistema complejo; transdisciplinar; promoción de la salud. 